\title{
Thermoelectric generator and solid-state battery for stand-alone microsystems
}

\author{
J P Carmo, J F Ribeiro, M F Silva, L M Goncalves and J H Correia \\ Department of Industrial Electronics, University of Minho, Campus Azurem, 4800-058 Guimaraes, \\ Portugal \\ E-mail: jcarmo@dei.uminho.pt
}

Received 17 April 2010, in final form 28 June 2010

Published 19 July 2010

Online at stacks.iop.org/JMM/20/085033

\begin{abstract}
This paper presents a thermoelectric (TE) generator and a solid-state battery for powering microsystems. Prototypes of TE generators were fabricated and characterized. The TE generator is a planar microstructure based on thin films of n-type bismuth telluride $\left(\mathrm{Bi}_{2} \mathrm{Te}_{3}\right)$ and p-type antimony telluride $\left(\mathrm{Sb}_{2} \mathrm{Te}_{3}\right)$, which were deposited using co-evaporation. The measurements on selected samples of $\mathrm{Bi}_{2} \mathrm{Te}_{3}$ and $\mathrm{Sb}_{2} \mathrm{Te}_{3}$ thin films indicated a Seebeck coefficient in the range of $90-250 \mu \mathrm{V} \mathrm{K}^{-1}$ and an in-plane electrical resistivity in the range of 7-17 $\mu \Omega \mathrm{m}$. The measurements also showed TE figures-of-merit, ZT, at room temperatures $\left(T=300 \mathrm{~K}\right.$ ) of 0.97 and 0.56 , for thin films of $\mathrm{Bi}_{2} \mathrm{Te}_{3}$ and $\mathrm{Sb}_{2} \mathrm{Te}_{3}$, respectively (equivalent to a power factor, $\mathrm{PF}$, of $4.87 \mathrm{~mW} \mathrm{~K}^{-2} \mathrm{~m}^{-1}$ and $2.81 \mathrm{~mW} \mathrm{~K}^{-2} \mathrm{~m}^{-1}$ ). The solid-state battery is based on thin films of: an anode of tin dioxide $\left(\mathrm{SnO}_{2}\right)$, an electrolyte of lithium phosphorus oxynitride $\left(\mathrm{Li}_{x} \mathrm{PO}_{y} \mathrm{~N}_{z}\right.$, known as LiPON) and a cathode of lithium cobaltate $\left(\mathrm{LiCoO}_{2}\right.$, known as $\mathrm{LiCO}$ ), which were deposited using the reactive RF (radio-frequency) sputtering. The deposition and characterization results of these thin-films layers are also reported in this paper.
\end{abstract}

(Some figures in this article are in colour only in the electronic version)

\section{Introduction}

Microsystem technology allows the fabrication of highly miniaturized systems in high volume at low costs, which contributes to making the systems virtually invisible and would result in an even more widespread application. One of the most important remaining challenges in these microsystems is to ensure a reliable supply of electrical power. The requirements generally imposed on reliability and overall system dimensions cannot be satisfied by external batteries [1]. Incorporating some kind of energy retrieving system in such devices is a highly promising solution to the problem. The use of freely available external energy sources for powering mobile devices is often referred to as energy harvesting [2, 3]. From the available renewable power sources, the three most important to harvest energy in remote micro/nanosystems are: vibration [4], photovoltaic [5] and thermal gradients [6]. The thermal-toelectric energy conversion does not require moving mechanical parts and has huge potential in a wide range of applications, because it provides compact and distributed power, is quiet in operation and it is usually environmentally friendly. These features are ample justification of the growth in the worldwide research efforts to bring the technology for thermoelectric (TE) device fabrication into the realms of microsystem technologies. Energy harvesting by taking advantage of temperature differences is a highly suitable solution for stand-alone microsystems. However solutions have to be found for the low efficiency of directly silicon-compatible materials before actual implementation can be considered. Any temperature difference between the two surfaces of a TE microgenerator can be converted into electrical energy using the Seebeck principle [7]. However, as the energy availability and power dissipation are not constant over time, the energy management is an even more important function and determines the potential for information processing [8]. This is the case of wireless sensor systems, which are usually in the idle state for most of the time and should deliver a peak load for only short periods of time. Moreover, the temperature gradient may not always be present. Therefore, the energy must be stored. A rechargeable thin-film battery of Li-ion type integrated in the system is highly suitable for that purpose. Since a minimum overall microsystem 
volume is required in many applications, the integration into an integrated circuit (IC) is desirable. Thin-film solid-state batteries are ideal candidates for such a purpose, because these have demonstrated very high lifetime in terms of chargingdischarging cycles and are intrinsically safe [13]. Moreover, either high voltage or high power is desirable in some applications, thus these features can be obtained from thinfilms solid-state batteries [9].

Hybrid devices composed of energy storage systems (e.g., the batteries) and energy scavengers in a small volume require some kind of energy management system [10]. The work presented by Lhermet et al [11] is the first of this kind, where a microbattery was deposited directly on a microchip (that makes energy management). Basically, the device is a microsystem composed of two (harvested) power sources (either thermal [12] or inductive [8] type), the microchip used to transform and to manage the harvested energy. The microchip also interfaces with the microbattery. The management operations are (1) the selection of external power source (when both are present) from which the battery must be charged; (2) to provide battery-compatible voltage levels; (3) to decide when to stop the charging of the battery; (4) to decide when to start the charging of the battery and finally, (5) to use the external source for powering without using the battery (thus, sparing it for situations when the external sources of power would not be present). The microbattery is of lithium type and it is composed of a stack of the following materials: TiSO (the anode), LiPON (the electrolyte) and lithium (the cathode). Further details concerning the fabrication of the microbattery can be found in $[9,10]$. The thermal-to-electric conversion subsystem is composed of bismuth and antimony telluride $\left(\mathrm{Bi}_{2} \mathrm{Te}_{3}\right.$ and $\left.\mathrm{Sb}_{2} \mathrm{Te}_{3}\right)$ TE pairs, which were deposited and patterned in lines and connected in series (by using titanium and aluminium metallic junctions) in order to provide the desired voltage for harvesting purposes [12].

In this sequence this paper presents a TE microconverter, which was especially designed and fabricated to meet the requirements listed above. The materials selection, the design and the layers for the thin-films solid-sate battery are also described in this paper.

\section{Thermoelectric generators}

\subsection{Overview}

Tellurium (Te) compounds are well-established room temperature TE materials, and macroscopic devices fabricated using conventional techniques are widely employed in industry for TE power generation and TE cooling [14]. Different deposition techniques for obtaining thin films of these materials can be found in the literature. Such techniques include the direct evaporation of the bulk materials made by Da Silva [15]. However, such techniques revealed that it was impossible to perform the deposition of $\mathrm{Bi}_{2} \mathrm{Te}_{3} / \mathrm{Sb}_{2} \mathrm{Te}_{3}$ thin films, due to the large differences in vapour pressure of bismuth/antimony and tellurium, whose consequence was a compositional gradient along the film thickness. In other examples, concerning the deposition of tellurium compounds, thin films have been made using thermal co-evaporation [16], DC magnetron sputtering [17], RF magnetron sputtering [18], flash evaporation [19], electrochemical deposition [20] and metal-organic chemical vapour deposition (MOCVD) [21].

As described in this paper, the co-evaporation of both ntype bismuth telluride $\left(\mathrm{Bi}_{2} \mathrm{Te}_{3}\right)$ and p-type antimony telluride $\left(\mathrm{Sb}_{2} \mathrm{Te}_{3}\right)$ provides thin films with excellent figures-of-merit [22], ZT, of 0.97 and 0.56 , respectively. The best available n-type thin films have (absolute value) a Seebeck coefficient in the range $150-250 \mu \mathrm{V} \mathrm{K}^{-1}$, resistivity of 10-17 $\mu \Omega \mathrm{m}$, thermal conductivity of about $1.3 \mathrm{~W} \mathrm{~m}^{-1} \mathrm{~K}^{-1}$ [23], carrier concentration $\approx 6 \times 10^{19} \mathrm{~cm}^{-3}$ and Hall mobility from 80 to $120 \mathrm{~cm}^{2} \mathrm{~V}^{-1} \mathrm{~s}^{-1}$. For the p-type thin films, the best available results include a Seebeck coefficient in the range 90$190 \mu \mathrm{V} \mathrm{K}^{-1}$, resistivity of 7-14 $\mu \Omega \mathrm{m}$, thermal conductivity about $1.7 \mathrm{~W} \mathrm{~m}^{-1} \mathrm{~K}^{-1}$ [23], carrier concentration $\approx 4 \times$ $10^{19} \mathrm{~cm}^{-3}$, Hall mobility from 120 to $170 \mathrm{~cm}^{2} \mathrm{~V}^{-1} \mathrm{~s}^{-1}$ and are slightly Te-rich (67-73\%, measured by EDX-energydispersive X-ray spectroscopy). It must be noted that these EDX measurements had a typical inaccuracy of $2 \%$ and $3 \%$ for the samples made of $\mathrm{Bi}_{2} \mathrm{Te}_{3}$ and $\mathrm{Sb}_{2} \mathrm{Te}_{3}$, respectively. However, and despite the associated inaccuracies, these values are similar to the best found in the literature for the bulk materials. The performance of TE devices depends on the figure of merit, ZT, of the material [24, 25], given by ZT = $\alpha . T /(\rho . \lambda)$, where $\alpha$ is the Seebeck coefficient, $\rho$ is the electrical resistivity, $\lambda$ is the thermal conductivity and $T$ is the temperature. Furthermore, in TE generators, the power factor is also used to measure the performance, $\mathrm{PF}=\alpha^{2} / \rho$ (W K $\mathrm{K}^{-2} \mathrm{~m}^{-1}$ ). In TE applications, a good film-to-substrate adhesion is obtained with Kapton films. This is due to its low thermal conductivity $\left(0.12 \mathrm{~W} \mathrm{~m}^{-1} \mathrm{~K}^{-1}\right)$ [26] and appropriate value of thermal expansion coefficient $\left(12 \times 10^{-6} \mathrm{~K}^{-1}\right)$ which closely matches the thermal expansion coefficient of the telluride films, thus reducing residual stress and increasing the adhesion.

\subsection{Fabrication}

Bismuth and antimony telluride thin films were fabricated using the co-evaporation resistive technique in a high-vacuum chamber with a pressure settled to $p=3 \times 10^{-6}$ mbar. The $\mathrm{Sb} / \mathrm{Bi}$ evaporation flow rates, $\operatorname{Fr}_{\mathrm{Sb}} / \mathrm{Fr}_{\mathrm{Bi}}\left(\AA_{\mathrm{s}}^{-1}\right)$, and the Te evaporation flow rate, $\mathrm{Fr}_{\mathrm{Te}}\left(\AA \mathrm{s}^{-1}\right)$, are the primary evaporation parameters. These parameters allow for tuning of the ratio of the evaporation flow rates, $R$, which is given by: $R=\mathrm{Fr}_{\mathrm{Te}} / \mathrm{Fr}_{\mathrm{Sb}}$ or $R=\mathrm{Fr}_{\mathrm{Te}} / \mathrm{Fr}_{\mathrm{Bi}}$, which is the amount of Te divided by the amount of $\mathrm{Sb}$ (or $\mathrm{Bi}$ ) that is actually being deposited at the substrate surface during co-evaporation. The power applied to each evaporation boat was controlled in such a way that constant bismuth and antimony evaporation flow rates, $\mathrm{Fr}_{(\mathrm{Bi})}$ and $\operatorname{Fr}_{(\mathrm{Sb})}\left(\AA_{\mathrm{s}^{-1}}\right)$, were maintained at $2 \AA \mathrm{s}^{-1}$, while the tellurium evaporation flow rate, $\operatorname{Fr}_{(\mathrm{Te})}\left(\AA \mathrm{s}^{-1}\right)$, was in the range 3-9 $\AA \mathrm{s}^{-1}$ to achieve optimum composition of $\mathrm{Bi}_{2} \mathrm{Te}_{3}$ and $\mathrm{Sb}_{2} \mathrm{Te}_{3}$ thin films. A quartz crystal oscillator was placed inside the chamber (for each thickness monitor) in order to have material deposited only from the boat it monitors. The information of each of these thickness monitors is the input of a 


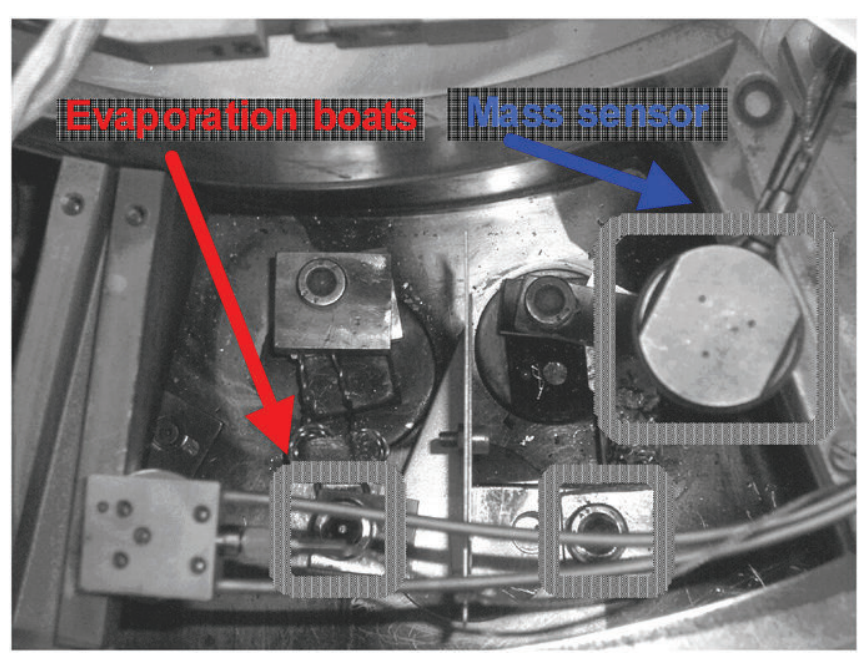

Figure 1. The co-evaporation system, where the boats and the mass sensors placed inside the chamber can be seen.

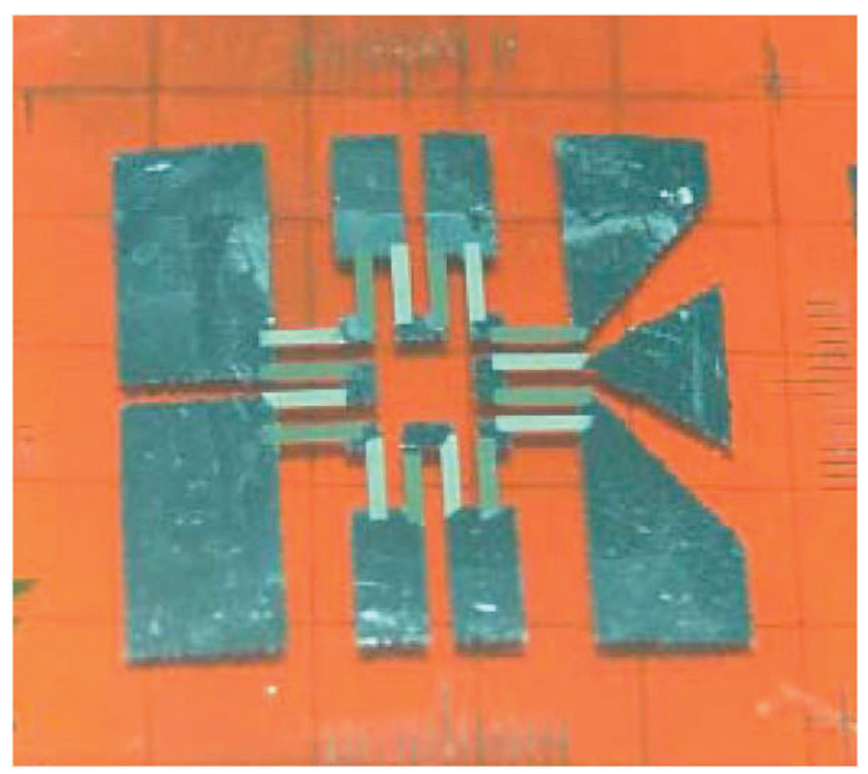

Figure 2. Photograph of a TE microconverter with eight pairs of TE elements, fabricated with bottom contacts.

PID controller (in real time) and is used to keep the evaporation rate constant. A metal sheet was placed between the two boats to partially separate the flows from the two materials and fully prevent mixing of both materials to occur at the quartz crystals (see the figure 1).

The substrates were heated to the temperature set point, $T_{\text {sub }}\left({ }^{\circ} \mathrm{C}\right)$, which was varied between $150{ }^{\circ} \mathrm{C}$ and $300{ }^{\circ} \mathrm{C}$. Several series of $\mathrm{Bi}_{2} \mathrm{Te}_{3}$ thin films were fabricated at substrate temperatures of $190{ }^{\circ} \mathrm{C}, 230{ }^{\circ} \mathrm{C}$ and $270{ }^{\circ} \mathrm{C}$. For the $\mathrm{Sb}_{2} \mathrm{Te}_{3}$ thin films, the substrate temperatures were $150{ }^{\circ} \mathrm{C}, 180{ }^{\circ} \mathrm{C}$ and $220^{\circ} \mathrm{C}$. In each deposition session, a set of four substrates were simultaneously subjected to the co-evaporation of thin-films materials. Also, all thin films were deposited for a required thickness of $1 \mu \mathrm{m}$.

Figure 2 shows a planar TE generator fabricated on top of a $25 \mu \mathrm{m}$ thickness Kapton foil. Their contacts can be deposited on top or bottom of the TE films.

\section{The solid-state battery}

\subsection{Solid-state battery overview and design}

Typically, a solid-state battery is fabricated by successive thin-film depositions of the metal current collectors, cathode, electrolyte and anode on a substrate [9-11, 27]. A variety of materials are available for the deposition of the cathode, electrolyte and anode. Lithium cobaltate $\left(\mathrm{LiCoO}_{2}\right)$ was the compound selected as the most suitable cathode due to its excellent electrochemical cycling stability, which is a result of the structural stability of the material, in which the layered cation ordering is extremely well preserved even after a repeated process of insertion and extraction of lithium ions [28]. Lithium cobaltate is the most widely used cathode material in thin-film Li-ion type of batteries, because it produces a very high potential [29] and it has superior performance in cycled charging/discharging (due to its high structural stability it can be cycled more than 500 times with a 80-90\% capacity retention). Compared to other materials (e.g., $\mathrm{LiMn}_{2} \mathrm{O}_{4}, \mathrm{LiNiO}_{2}$ ), lithium cobaltate is easy to fabricate and has a relatively high charge storage capacity.

Thin-film solid electrolytes for thin-film batteries are required to have high ionic conductivity, a negligible electronic conductivity and be stable in contact with the anode and cathode electrodes [29]. These requirements are met if the battery electrolyte is lithium phosphorous oxynitride (LiPON). The widespread use of this compound as electrolyte material is due to the exceptional electrochemical stability and very good conductivity of lithium ions [30]. Moreover, LiPON films present an electronic resistivity greater than $10^{14} \Omega \mathrm{cm}$, which helps to minimize the short circuit self-discharge and increasing the battery's lifetime [31].

A number of metals and semiconductors (e.g., aluminium, tin and silicon) react with lithium to form alloys by electrochemical processes in a reversible way. These are the most suitable candidates for use an anode in lithium-ion batteries [32]. Tin dioxide $\left(\mathrm{SnO}_{2}\right)$ was chosen for the anode material due to their high-lithium storage capacity and low potential of lithium ion intercalation. A tin dioxide anode can give a maximum theoretical $781 \mathrm{~mA} \mathrm{~h} \mathrm{~g}^{-1}$ charge-storage capacity [32]. Also, the average resistivity of tin dioxide films are in the range $10-17 \mathrm{~m} \Omega \mathrm{cm}$ for films with a thickness less than $100 \mathrm{~nm}$ and $5-9 \mathrm{~m} \Omega \mathrm{cm}$ for the thickness more than $100 \mathrm{~nm}$.

\subsection{Thin-film deposition}

The material layers of the solid-state battery were all obtained by thin-film deposition, using RF magnetron sputtering. The sputtering system used is composed of a $2^{\prime \prime}$ planar magnetron sputtering cathode and a R301-MKII (300 W RF generator at $13.56 \mathrm{MHz}$ ) to generate the plasma. The control and measurements of flow rate of the gases (argon and oxygen or nitrogen) was done with a MKS type $246 C$ single channel power supply/readout system, through an analogue MKS mass flow controller of type $1179 A$ and from an analogue MKS mass flow meter of type $179 \mathrm{~A}$. 
Table 1. Properties of the selected $\mathrm{Bi}_{2} \mathrm{Te}_{3}$ films.

\begin{tabular}{llllcccl}
\hline & $T_{\text {sub }}$ & \multicolumn{2}{c}{$\%$ Te by } & & & \\
$\mathrm{TF}$ & $\left({ }^{\circ} \mathrm{C}\right)$ & $R$ & $\mathrm{EDX}$ & $\alpha$ & $\rho$ & $\mathrm{PF}$ & $\mathrm{ZT}$ \\
\hline 1 & 190 & 1.7 & - & -180 & 16.6 & 1.95 & 0.4 \\
2 & 230 & 2.1 & 62.8 & -156 & 11.3 & 2.16 & 0.43 \\
3 & 230 & 3.0 & 62.2 & -152 & 13.4 & 1.72 & 0.34 \\
4 & 270 & 3.2 & 62.0 & -248 & 12.6 & 4.87 & 0.97 \\
5 & 270 & 3.9 & - & -220 & 10.6 & 4.57 & 0.91 \\
\hline
\end{tabular}

Table 2. Properties of the selected $\mathrm{Sb}_{2} \mathrm{Te}_{3}$ films.

\begin{tabular}{|c|c|c|c|c|c|c|c|}
\hline $\mathrm{TF}$ & $\begin{array}{l}T_{\text {sub }} \\
\left({ }^{\circ} \mathrm{C}\right)\end{array}$ & $R$ & $\begin{array}{l}\text { \% Te by } \\
\text { EDX }\end{array}$ & $\alpha$ & $\rho$ & PF & $\mathrm{ZT}$ \\
\hline 1 & 150 & 1.47 & 54.5 & 91 & 7.6 & 1.09 & 0.22 \\
\hline 2 & 150 & 1.67 & 61.4 & 140 & 14.0 & 1.40 & 0.28 \\
\hline 3 & 220 & 2.50 & 67.3 & 156 & 9.2 & 2.66 & 0.53 \\
\hline 4 & 220 & 3.18 & 73.5 & 188 & 12.6 & 2.81 & 0.56 \\
\hline
\end{tabular}

Several tin dioxide $\left(\mathrm{SnO}_{2}\right)$ layers were fabricated by sputtering in order to obtain the optimum settings for the deposition of this material. The best settings for argon (Ar) and oxygen $\left(\mathrm{O}_{2}\right)$ gases flows are $20 \mathrm{sccm}$ at a pressure of $10^{-2}$ mbar in the chamber. At these conditions a set of samples with deposited tin dioxide thin films were obtained with a film thickness of $630 \mathrm{~nm}$.

The deposition of lithium cobaltate $\left(\mathrm{LiCoO}_{2}\right)$ thin films was performed at a sputtering chamber pressure of $10^{-6}$ mbar. The argon and oxygen flows in the plasma were kept at $50 \mathrm{sccm}$ and $10 \mathrm{sccm}$, respectively, in all experiments.

The material selected for the electrolyte was lithium phosphorous oxynitride $\left(\mathrm{Li}_{3} \mathrm{PO}_{4} \mathrm{~N}\right)$. However, the target material used in the sputtering sessions was lithium phosphorus tetraoxide $\left(\mathrm{Li}_{3} \mathrm{PO}_{4}\right)$. Thus, LiPON was obtained by reactive RF sputtering the $\mathrm{Li}_{3} \mathrm{PO}_{4}$ target in a nitrogen $\left(\mathrm{N}_{2}\right)$ and argon (Ar) atmosphere at a pressure of $3 \times 10^{-3}$ mbar.

\section{Experimental results and discussion}

\subsection{Thermoelectric generator}

The in-plane electrical resistivity was measured using the conventional four-probe van der Pauw method, at room temperature. The thermal conductivity was measured using the method proposed by Völklein [23], and it was $1.3 \mathrm{~W} \mathrm{~m}^{-1}$ $\mathrm{K}^{-1}$ and $1.8 \mathrm{~W} \mathrm{~m}^{-1} \mathrm{~K}^{-1}$ for the $\mathrm{Bi}_{2} \mathrm{Te}_{3}$ and $\mathrm{Sb}_{2} \mathrm{Te}_{3}$ films, respectively. The measurements of the Seebeck coefficient were made by connecting one side of the film to a fixed temperature (heated metal block) and the other side to a heat sink at room temperature.

Tables 1 and 2 show the experimental results in the selected samples of $\mathrm{Bi}_{2} \mathrm{Te}_{3}$ and $\mathrm{Sb}_{2} \mathrm{Te}_{3}$ thin films (TFs), such as the corresponding figures-of-merit, ZT, and the power factors, $\mathrm{PF}\left(\mathrm{W} \mathrm{K}^{-2} \mathrm{~m}^{-1}\right.$ ). It must be noted that in all the tables, the quantities $\alpha, \rho$ and $\mathrm{PF}$ are expressed respectively in $\mu \mathrm{V} \mathrm{K}^{-1}$, $\mu \Omega \mathrm{m}$ and $\mathrm{mW} \mathrm{K}^{-2} \mathrm{~m}^{-1}$ [33]. Also, the ZTs were obtained at $300 \mathrm{~K}$.

Tables 1 and 2 show discrepancies, because the different sets of thin films were obtained under different co-evaporation
Table 3. Comparison of the experimental results obtained for the best $\mathrm{Bi}_{2} \mathrm{Te}_{3}$ thin-film sample with the up-to-date state-of-the-art.

\begin{tabular}{lcccl}
\hline Deposition method & $\alpha$ & $\rho$ & PF & Reference \\
\hline Co-evaporation & -248 & 12.6 & 4.87 & This work \\
Flash evaporation & -252 & 18.2 & 3.49 & {$[19]$} \\
DC magnetron sputtering & -201 & 340 & 0.12 & {$[17]$} \\
RF magnetron sputtering & -248 & 7194 & 0.41 & {$[18]$} \\
\hline
\end{tabular}

Table 4. Comparison of the experimental results obtained for the best $\mathrm{Sb}_{2} \mathrm{Te}_{3}$ thin-film sample with the up-to-date state-of-the-art.

\begin{tabular}{lllll}
\hline Deposition method & $\alpha$ & $\rho$ & PF & Reference \\
\hline Co-evaporation & 188 & 12.6 & 2.81 & This work \\
DC magnetron sputtering & 304 & 5404 & $26 \times 10^{-2}$ & {$[17]$} \\
Electrodeposition & 320 & 50 & 5.6 & {$[20]$} \\
\hline
\end{tabular}

conditions. The explanation for a wide range of deposition conditions was to identify the situation(s) with the best combination(s) of results (e.g., the best values of $\alpha, \rho$ and $\mathrm{ZT}$ ), in order to be applied in the fabrication of the final TE converter. From these two tables, it was possible to observe that the thin films with the best TE properties were obtained with substrate temperatures of $270^{\circ} \mathrm{C}$. The deposition at substrate temperatures of $270^{\circ} \mathrm{C}$ with a $\mathrm{Bi}$ evaporation rate of $2 \AA \mathrm{s}^{-1}$ and Te evaporation rate of $6.4 \AA \mathrm{s}^{-1}$ (hence $R=$ 3.2 ) resulted in thin films of optimum composition to result in a TE power factor of $\mathrm{PF}=4.87 \times 10^{-3} \mathrm{~W} \mathrm{~K}^{-2} \mathrm{~m}^{-1}$. The EDX analysis on thin films with these evaporation parameters confirms a near-stoichiometric composition of the material (35-40\% Bi and 65-60\% Te). It was observed that even with different substrate temperatures, it is possible to obtain thin films with a higher power factor when the composition is slightly rich on tellurium (measured by EDX), e.g., for 60-65\% of Te. For the case of $\mathrm{Sb}_{2} \mathrm{Te}_{3}$ thin films, the best TE properties were obtained with substrate temperatures of $220^{\circ} \mathrm{C}$ with an Sb evaporation rate of $2 \AA \mathrm{s}^{-1}$ and a Te evaporation rate of $6.4 \AA \mathrm{s}^{-1}$ (thus, $R=3.2$ ). Such evaporation parameters resulted in a tellurium rich composition (also measured by EDX) of the compound with $25-35 \%$ of $\mathrm{Sb}$ and $65-75 \%$ of Te. An increased TE power factor of $\mathrm{PF}=2.81 \times 10^{-3} \mathrm{~W} \mathrm{~K}^{-2} \mathrm{~m}^{-1}$ was measured in the case of tellurium rich films (composition with $70 \% \mathrm{Te}$ ). The measurements done on selected samples also showed a Seebeck coefficient with an absolute value in the range $90-250 \mu \mathrm{V} \mathrm{K}^{-1}$, an in-plane electrical resistivity of 7-17 $\mu \Omega \mathrm{m}$ and figures-of-merit, $\mathrm{ZT}$, at room temperatures $\left(T=300 \mathrm{~K}\right.$ ) of 0.97 and 0.56 for $\mathrm{Bi}_{2} \mathrm{Te}_{3}$ and $\mathrm{Sb}_{2} \mathrm{Te}_{3}$ thin films, respectively.

Tables 3 and 4 list the major experimental results of deposited $\mathrm{Bi}_{2} \mathrm{Te}_{3} / \mathrm{Sb}_{2} \mathrm{Te}_{3}$ thin films, as well as those obtained from the up-to-date work in the literature [17-20]. It can be seen in table 3 , the best performance in all TE aspects $(\alpha, \rho$ and $\mathrm{PF}$ ) of the deposited $\mathrm{Bi}_{2} \mathrm{Te}_{3}$ thin films, relatively to those obtained with other techniques [17-19].

\subsection{Layer material of the solid-state battery}

The crystalline structure of the selected sample of tin dioxide films was characterized by x-ray diffraction (XRD) and 

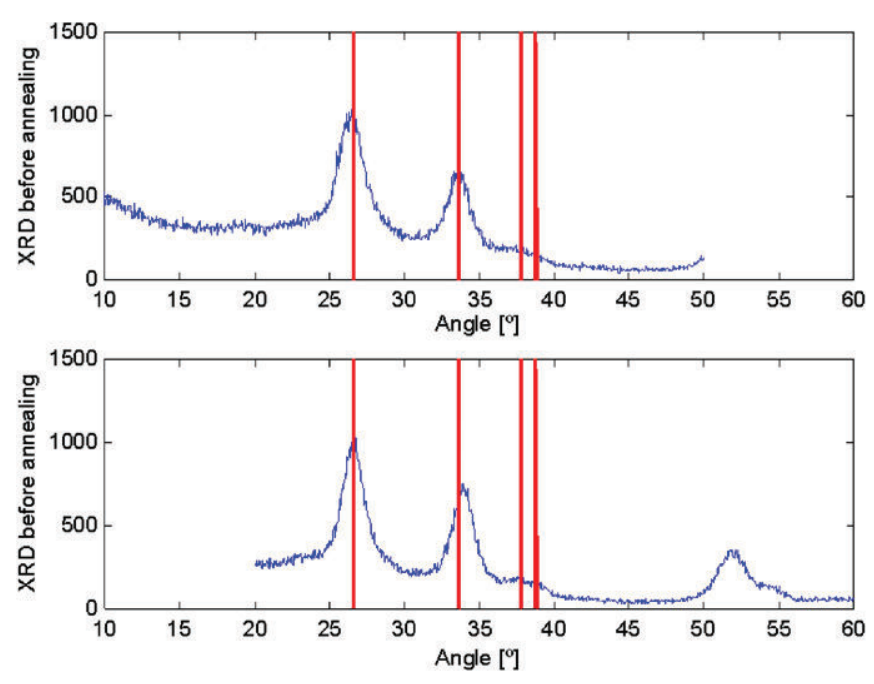

Figure 3. XRD spectra of the selected sample of tin dioxide thin film before (top) and after (bottom) annealing at $300{ }^{\circ} \mathrm{C}$.
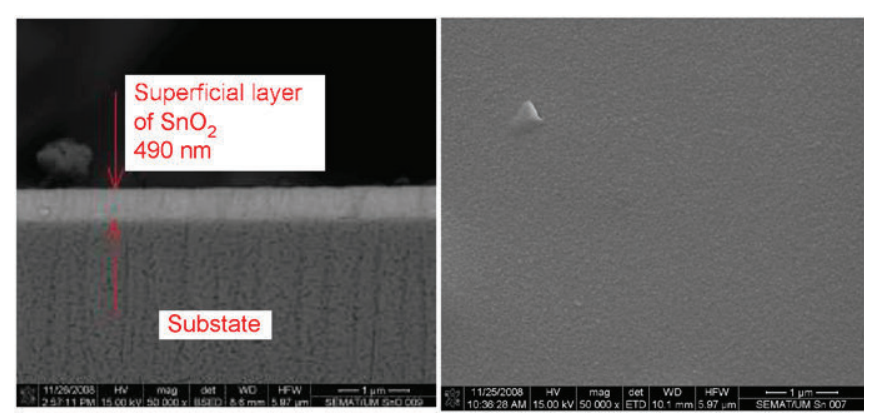

Figure 4. Cross-section and surface SEM images of the selected sample of tin dioxide thin film deposited under the optimal process conditions.

diffractograms were recorded from $10^{\circ}$ to $60^{\circ}$ with a step of $0.04^{\circ}$. These measurements were made before (in the asdeposited selected sample) and after annealing of the thin-film selected sample at $300^{\circ} \mathrm{C}$. Figure 3 shows the XRD spectra for the selected sample of tin dioxide thin films, before (top plot) and after the annealing (bottom plot). It must be noted that the clustering of atoms at elevated temperature results in increased crystal dimensions, which increases the electrical conductivity of the material. In contrast to electrolytes, it is desirable to have anodes and cathodes with the highest possible conductivity. This effect is confirmed in the XRD plots of figure 4, since the annealed sample presents crystalline structure of single phase tin dioxide has a sharper peak in the XRD as compared to the non-annealed sample, which indicates a larger grain size in the structure. Thus, high conductance thin films of tin dioxide for the cathode are expected. The measurements showed thin films of $\mathrm{SnO}_{2}$ with a resistivity in the range $10^{-3}-10^{-1} \mu \Omega \mathrm{mm}$ before annealing. After annealing the resistivity decreased to $10^{-4} \mu \Omega \mathrm{mm}$.

The table 5 compares the characteristics of the selected sample with the state-of-the-art [34-37]. It is important to note that the tin dioxide thin films of this work have the lowest value for the resistivity, even with the smallest thin-films' thickness. Utsumi et al [36] and Ma et al [37] use lower annealing temperatures, however combining annealing with
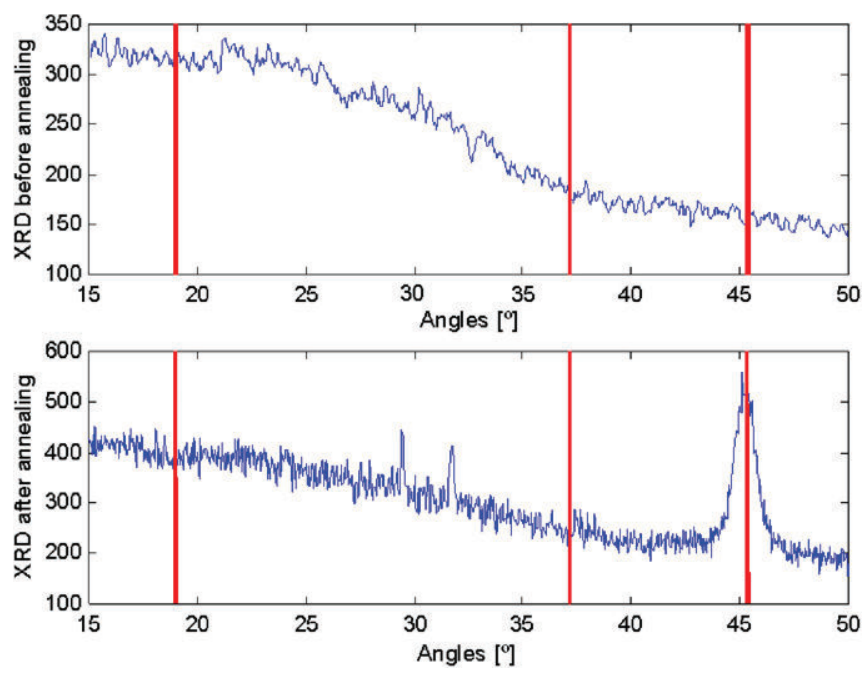

Figure 5. XRD spectra of the selected sample of lithium cobaltate thin film before (top) and after (bottom) annealing at $600{ }^{\circ} \mathrm{C}$.

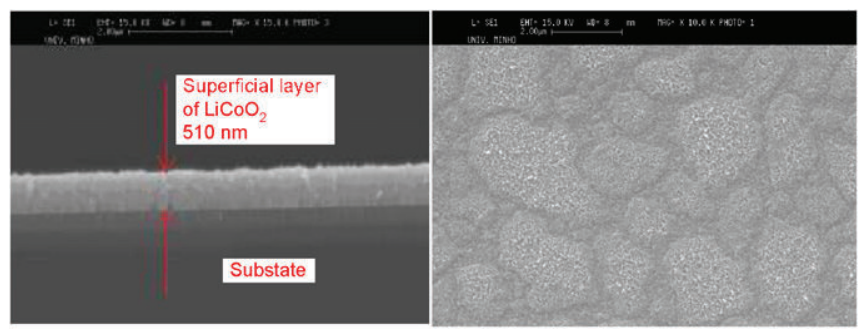

Figure 6. Cross-section and surface SEM images of a lithium cobaltate thin film deposited under the optimal process conditions.

Table 5. Comparison of the experimental results obtained for the best $\mathrm{SnO}_{2}$ thin-film sample with the most up-to-date state-of-the-art.

\begin{tabular}{|c|c|c|c|c|}
\hline Deposition method & $\rho(\mu \Omega \mathrm{mm})$ & $T_{\text {annl }}(\mathrm{oC})$ & $\begin{array}{l}\text { TFT } \\
(\mathrm{nm})\end{array}$ & Reference \\
\hline $\begin{array}{l}\text { RF reactive magnetron } \\
\text { sputtering }\end{array}$ & $10^{-4}$ & 300 & $<600$ & This work \\
\hline Filtered arc plasma & $10^{-3}$ & - & $<100$ & [34] \\
\hline Pulsed laser & - & $150-400$ & - & [35] \\
\hline DC sputtering & $36 \times 10^{-4}$ & 200 & 150 & [36] \\
\hline RF sputtering & $3.7 \times 10^{-4}$ & $30-220$ & 285 & [37] \\
\hline
\end{tabular}

deposition, which significantly complicated the control of the deposition. The SEM images presented in figure 4 are for a selected sample of a tin dioxide thin film deposited under the optimal settings.

Figures 5 and 6 show the XRD spectra and SEM images of the selected sample of lithium cobaltate thin film that were deposited at a pressure of $10^{-2}$ mbar. The diffractograms in figure 5 showed a predominance of lithium cobaltate compound in the composition of the selected sample. This observation is in accordance with the XRD plots presented by Bates et al [38]. The apparent grain boundaries in the surface SEM of the figure 6 are a result of the annealing process which was carried out by heating the thin-film substrate at a temperature of $300{ }^{\circ} \mathrm{C}$. Despite it, a detailed analysis allows the observation of a crystalline structure that explains the XRD peaks of lithium cobaltate in the annealed samples. 

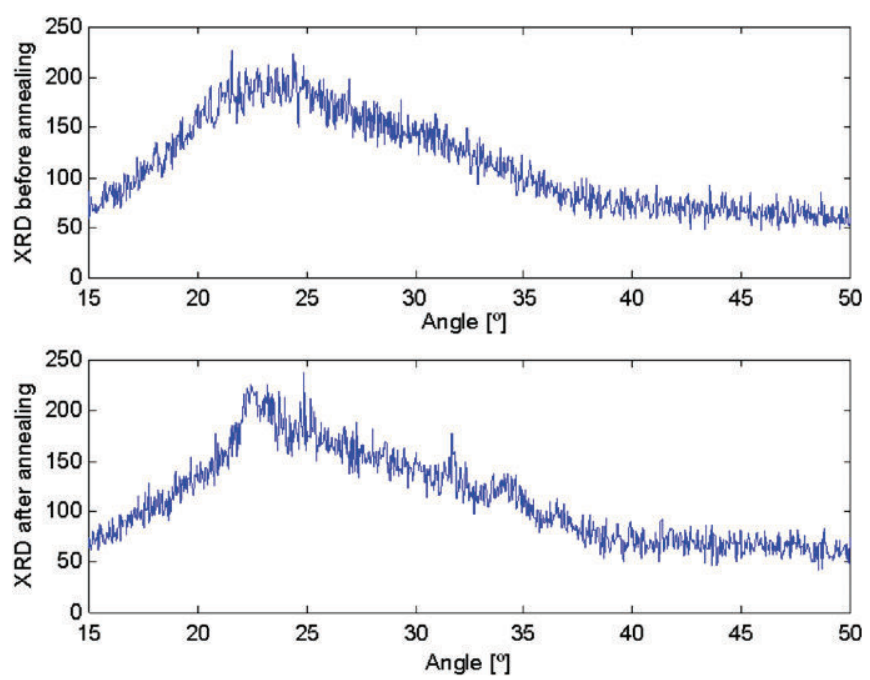

Figure 7. XRD spectra of the selected sample of LiPON thin film before (top) and after (bottom) annealing at $550{ }^{\circ} \mathrm{C}$.

The best performing batteries have electrolytes with the highest ionic conduction. Thus, the best suitable material and its properties must be explored. It is a generally accepted fact that amorphous electrolytes have superior properties over crystalline electrolytes with respect to the ionic conduction. Some of the reasons for preferring electrolytes to amorphous structures are: the selection over a huge range of possible compositions and the easy deposition of isotropic thin films without grain boundaries. This means that the amorphous structures of the amorphous materials will result in thin films with high ionic conduction as compared to crystalline structures. The XRD diffractogram shown in figure 7 was obtained in LiPON thin films before (as-deposited thin films) and after the annealing at $550{ }^{\circ} \mathrm{C}$. Both plots confirm the amorphous structure (the absence of any crystalline structure) of the LiPON thin films in the both situations. As suggested by Hamon et al [39] LiPON thin films with an amorphous structure are the most suitable candidates for achieving high ionic conductivity. Consequently, these are the ones with the superior features for use as electrolytes in solid-state thin-films batteries. Moreover, the similar XRD results observed for the as-deposited (before annealing) and the annealed selected samples of deposited LiPON thin films are evidence of the feasibility to fabricate the battery. Despite annealing to optimize the properties of LiPON, the amorphous structure in the solid-state electrolyte is maintained.

The ionic conductivity measurement on a selected sample of LiPON was done using the procedure described by Hamon et al [39] and Park et al [40]. A signal with a peak-to-peak amplitude of $25 \mathrm{mV}$ was used to measure the impedance of the selected sample for several values of frequency (from $0.5 \mathrm{~Hz}$ to $65 \mathrm{kHz})$. Then, both real $\left(Z_{\text {real }}\right)$ and imaginary $\left(Z_{\text {imag }}\right)$ parts of the measured impedances were respectively projected in the $x$-axis and $y$-axis, in order to obtain a $2 \mathrm{D}$ Nyquist plot. Two Nyquist plots for two room temperatures (295.95 K and 298.95 K) were obtained and are both depicted in figure 8 .

The diameter of the semi-circle indicates the resistance, $R(\Omega)$, of the electrolyte, whose values were obtained with the

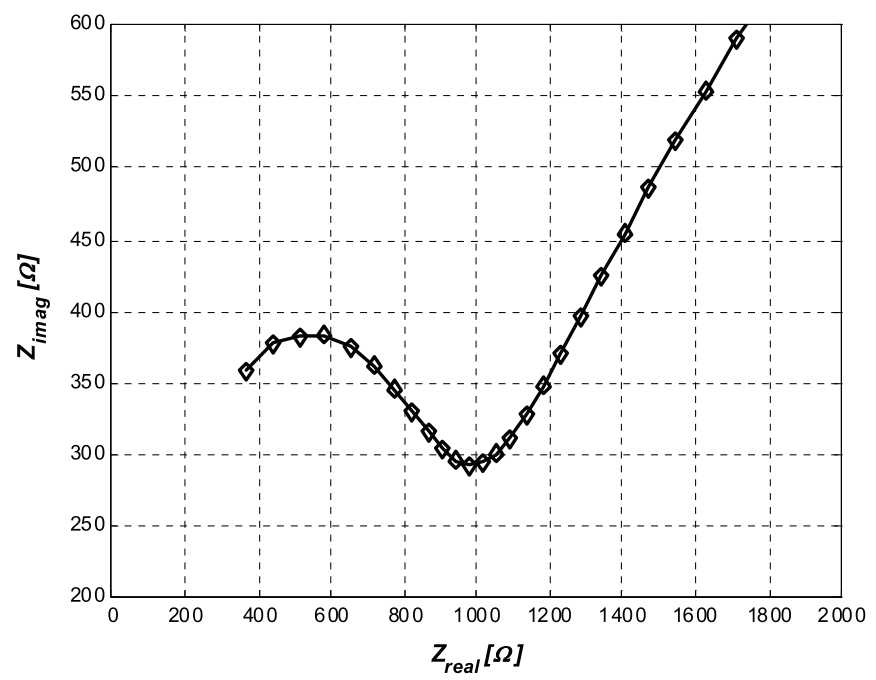

(a)

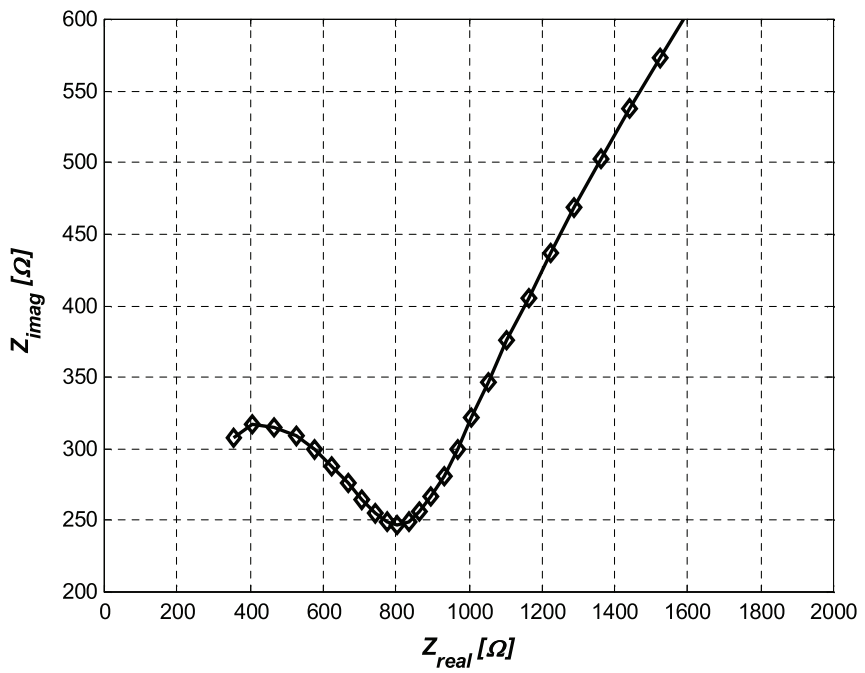

(b)

Figure 8. AC impedance analysis of LiPON electrolyte, showing Nyquist plots for room temperatures of (a) $295.95 \mathrm{~K}$ and (b) $298.95 \mathrm{~K}$.

help of the Autolab software. The equation that describes the ion conductivity, $\sigma\left(\mathrm{S} \mathrm{cm}^{-1}\right)$, of LiPON is: $\sigma=(d / A) / R$, where $d$ is the thickness of thin film, $A\left(\mathrm{~m}^{2}\right)$ is the LiPON-tip (the tip assures the electrical connection between the LiPON and the read-out instrumentation) interface area and $R$ is the obtained resistance. The measurements showed ionic conductivities of $9.3 \times 10^{-8} \mathrm{~S} \mathrm{~cm}^{-1}$ and $1.3 \times 10^{-7} \mathrm{~S}$ $\mathrm{cm}^{-1}$ at temperatures of $295.95 \mathrm{~K}$ and $298.95 \mathrm{~K}$, respectively. Figure 8 allows us to obtain these two conclusions: (1) the ionic conductivity at about room temperature increases with temperature and (2) an increased slope of the straight line in the Nyquist plot also indicates an increased ionic conductivity.

\section{Conclusions}

This paper presented a planar TE generator. This TE microstructure is based on thin films of $\mathrm{Bi}_{2} \mathrm{Te}_{3}$ and $\mathrm{Sb}_{2} \mathrm{Te}_{3}$, which were selected due to their highest figure-of-merit, ZT, 
at room temperature. The battery layers (anode, electrolyte and cathode) for the solid-state battery were deposited using the reactive RF sputtering technique. The materials for the cathode, electrolyte and anode were lithium cobaltate, lithium phosphorous oxynitride and tin dioxide, respectively. The deposition process and setup parameters were adjusted to obtain maximum performance of materials. The deposited films were characterized in order to obtain a specification in terms of the homogeneity, composition and electrical properties, as a function of the flow rates of gases during sputtering.

The target application of the TE generator and the solidstate battery is for integration with stand-alone microsystems.

\section{Acknowledgment}

This work was fully supported by FCT/PTDC/EEAENE/66855/2006 project.

\section{References}

[1] Mateu L, Codrea C, Lucas N, Pollak C and Spies P 2007 Human body energy harvesting thermogenerator for sensing applications Proc. 2007 Int. Conf. on Sensor Technologies and Applications pp 366-72

[2] Colomer-Ferrarons J, Brufau J, Miribel-Catala P, Saiz-Vela A, Puig-Vidal M and Samitier J 2008 Power-conditioning circuitry for a self-powered system based on micro PZT generators in a $0.13-\mu \mathrm{m}$ low-voltage low-power technology IEEE Trans. Ind. Electron. 55 3249-57

[3] Collins L 2006 Harvest for the world IEE Power Eng. J. 20 34-7

[4] Mateu L and Moll F 2006 Appropriate charge control of the storage capacitor in a piezoelectric energy harvesting device for discontinuous load operation Sensors Actuators A $132302-10$

[5] Dondi D, Bertacchini A, Brunelli D, Larcher L and Benini L 2008 Modeling and optimization of a solar energy harvester system for self-powered wireless sensor networks IEEE Trans. Ind. Electron. 55 2759-66

[6] Min G and Rowe D M 2007 Conversion efficiency of thermoelectric combustion systems IEEE Trans. Energy Convers. 32 528-34

[7] Bell L 2008 Cooling, heating, generating power, and recovering waste heat with thermoelectric systems Science 321 1457-61

[8] Lhermet H, Condemine C, Salot R, Plissonnier M, Bacquet S and Audebert P 2007 On chip post-processed microbattery powered with RF and thermal energy through a power management circuit Proc. IEEE Int. Conf. on Integrated Circuit Design an Technology pp 184-6

[9] Oukassi S, Gagnard X, Salot R, Bancel S and Pereira-Ramos J P 2006 Above IC micro-power generators for RF-MEMS Proc. Symp. Design Test Integration \& Packaging of MEMS/MOEMS pp 1-4

[10] Salot R, Bancel S, Martin S, Savelli G, Salvi C and Plissonnier M 2006 Thermoelectric and microbattery hybrid system with its power management Proc. Symp. Design Test Integration \& Packaging of MEMS/MOEMS pp 349-53

[11] Lhermet H, Condemine C, Plissonnier M, Salot R, Audebert and Rosset M 2008 Efficient power management circuit: from thermal energy harvesting to above-IC microbattery energy storage IEEE J. Solid-State Circuits 43 246-55
[12] Savelli G, Plissonnier M, Bablet J, Salvi C and Fournier J M 2006 Energy conversion using new thermoelectric generator Proc. Symp. Design Test Integration \& Packaging of MEMS/MOEMS pp 369-74

[13] Armand M and Tarascon M 2008 Building better batteries Nature 451 652-7

[14] Zou H, Rowe D M and Min G 2001 Preparation and characterization of p-type $\mathrm{Sb}_{2} \mathrm{Te}_{3}$ and n-type $\mathrm{Bi}_{2} \mathrm{Te}_{3}$ thin films grown by co-evaporation J. Vac. Sci. Technol. A 19 899-903

[15] da Silva L W, Massoud K and Uher C 2005 Thermoelectric performance of films in the antimony-tellurium and bismuth-tellurium systems J. Appl. Phys. 97114903

[16] Zou H, Rowe D M and Williams S G 2002 Peltier effect in a co-evaporated $\mathrm{Sb}_{2} \mathrm{Te}_{3}(\mathrm{P})-\mathrm{Bi}_{2} \mathrm{Te}_{3}(\mathrm{~N})$ thin-films thermocouple Thin Solid Films 408 270-4

[17] Bourgault D, Garampon C, Caillault N, Carbone L and Aymami J A 2008 Thermoelectric properties of n-type $\mathrm{Bi}_{2} \mathrm{Te}_{2.7} \mathrm{Se}_{0.3}$ and p-type $\mathrm{Bi}_{0.5} \mathrm{Sb}_{1.5} \mathrm{Te}_{3}$ thin films deposited by direct current magnetron sputtering Thin Solid Films $5168579-83$

[18] Huang H, Luan W and Tu S 2009 Influence of annealing on thermoelectric properties of bismuth telluride films grown via radio frequency magnetron sputtering Thin Solid Films 517 3731-34

[19] Takashiri M, Miyazaki K and Tsukamoto H 2008 Structural and thermoelectric properties of fine-grained $\mathrm{Bi}_{0.4} \mathrm{Te}_{3.0} \mathrm{Sb}_{1.6}$ thin films preferred orientation deposited by flash evaporation method Thin Solid Films 516 6336-43

[20] Lim S, Kim M and Oh T 2009 Thermoelectric properties of the bismuth-antimony-telluride and the antimony-telluride films processed by electrodeposition for micro-device applications Thin Solid Films 517 4199-203

[21] Foucaran A 1998 Flash evaporated layers of $\left(\mathrm{Bi}_{2} \mathrm{Te}_{3}-\mathrm{Bi}_{2} \mathrm{Se}_{3}\right)(\mathrm{N})$ and $\left(\mathrm{Bi}_{2} \mathrm{Te}_{3}-\mathrm{Sb}_{2} \mathrm{Te}_{3}\right)(\mathrm{P})$ Mater. Sci. Eng. B 52 154-61

[22] Min G and Rowe D M 1999 Cooling performance of integrated thermoelectric microcooler Solid-State Electron. 43 923-9

[23] Völklein F 2000 Characterisation of the thermal properties of bulk and thin-film materials by using diagnostic microstructures Proc. Symp. on Microtechnology in Metrology and Metrology in Microsystems

[24] Venkatasubramanian R, Siivola E, Colpitts T and O'Quinn B 2001 Thin-film thermoelectric devices with high room-temperature figures of merit Nature 413 597-602

[25] Wijngaards D D L and Wolffenbuttel R F 2005 Thermo-electric characterization of APCVD PolySi $\mathrm{Si}_{0.7} \mathrm{Ge}_{0.3}$ for IC-compatible fabrication of integrated lateral Peltier elements IEEE Trans. Electron Devices 52 1014-25

[26] DuPont ${ }^{\mathrm{TM}} 2006$ Kapton HN Polymide Film Technical Data Sheet

[27] Carmo J, Rocha R P, Silva A F, Gonçalves L M and Correia J H 2009 Integrated thin-film rechargeable battery in a thermoelectric scavenging microsystem Proc. Int. Conf. on Power Engineering Energy and Electrical Drives pp 348-51

[28] Park M, Hyuna S-H, Namc S-C and Chod S B 2008 Performance evaluation of printed $\mathrm{LiCoO}_{2}$ cathodes with PVDF-HFP gel electrolyte for lithium ion microbatteries Electrochim. Acta 53 5523-7

[29] Patil A, Patila V, Shina D W, Choia J-W, Paika D-S and Yoon S J 2008 Issue and challenges facing rechargeable thin film lithium batteries Mater. Res. Bull. 43 1913-42

[30] Dudney N J and Neudecker B J 1999 Solid state thin-films lithium battery systems Solid State Mater. Sci. 4 479-82

[31] Dudney N J 2005 Solid-state thin-films rechargeable batteries Mater. Sci. Eng. B 116 245-9 
[32] Wang Z, Chena G and Xia D 2008 Coating of multi-walled carbon nanotube with $\mathrm{SnO}_{2}$ films of controlled thickness and its application for Li-ion battery J. Power Sources 184 432-436

[33] Carmo J, Gonçalves L M and Correia J H 2010 Thermoelectric micronconverter for energy harvesting systems IEEE Trans. Ind. Electron. 57 861-7

[34] Zhitomirsky V N, Çetinörgü E, Boxman R L and Goldsmith S 2008 Proprieties of $\mathrm{SnO}_{2}$ films fabricated using a rectangular filtered vacuum arc plasma source Thin Solid Films $\mathbf{5 1 6}$ 5079-86

[35] Khandelwal R, Singh A P, Kapoor A, Grigorescu S, Miglietta P, Stankova N E and Perrone A 2009 Effects of deposition temperature on the structural and morphological properties of $\mathrm{SnO}_{2}$ films fabricated by pulsed laser deposition Opt. Laser Technol. 41 89-93

[36] Utsumi K, Ligusa H, Tokumaru R, Song P K and Shigesato Y 2003 Study on $\mathrm{In}_{2} \mathrm{O}_{3}-\mathrm{SnO}_{2}$ transparent and conductive films prepared by d.c. sputtering using high density ceramic targets Thin Solid Films 445 229-34

[37] Ma J, Hao X, Ma H, Xu X, Yang Y, Huang S, Zhang D and Cheng $\mathrm{C} 2002 \mathrm{RF}$ magnetron sputtering $\mathrm{SnO}_{2}: \mathrm{Sb}$ films deposited on organic substrates Solid-State Commun. $121345-9$

[38] Bates J B, Dudney N J, Neudecker B, Ueda A and Evans C D 2000 Thin-film lithium and lithium-ion batteries Solid State Ion. 135 33-45

[39] Hamon Y, Douard A, Sabary F, Marcel C, Vinatier P, Pecquenard B and Levasseur A 2006 Influence of sputtering conditions on ionic conductivity of LiPON thin films Solid State Ion. 177 257-61

[40] Park H Y, Nam S S, Lim Y C, Choi K G, Lee K C, Park G B, Lee S-R, Kim H P and Cho S B 2006 Effects of sputtering pressure on the characteristics of lithium ion conductive lithium phosphorous oxynitride thin-films J. Electroceram. 17 1023-30 